\title{
A review of flexible management for patients with Congestive Cardiac Failure (CCF): The implementation of post discharge Rapid Response Teams (RRTs)
}

\author{
Muhammad Afiq Roslim \\ RN, BSc (Hons) \\ University of Manchester \\ Singapore
}

\author{
Dr John Costello \\ Associate Professor \\ University of Manchester \\ Manchester, United Kingdom
}

\begin{abstract}
Hospitalized patients with Congestive Cardiac Failure (CCF) often experience an acute decline in their conditions post- discharge usually preceded by changes in their vital signs (for eg. respiratory rate, heart rate, blood pressure and temperature). Should these subtle changes go unrecognized, can have serious implications for patient mortality and morbidity. However, as this article outlines, implications such as these may be prevented by interventions being made by specialist practitioners known as Rapid Response Teams (RRTs). The role of such teams in the postdischarge period is to promptly identify patients at risk of further clinical decline and initiate appropriate responses to prevent serious adverse events. The aim of this article is to briefly review the management of patients with CCF in the hospital and propose the initiation of RRTs post-discharge for CCF patients in Singapore. Moreover, the article proposes that such teams should be implemented in Singapore as a positive contribution to the care and treatment of people with CCF. RRTs were conceptualized as a consultative service to bring critical care expertise to the management of patients with $\mathrm{CCF}$ following discharge from the hospital. This article considers the challenges and barriers to the implementation of RRTs in a Singaporean context by using SWOT analysis to consider the potential in terms of the both the benefits and the difficulties that such an initiative can produce.
\end{abstract}

Keywords- congestive cardiac failure, rapid response team, postdischarge

\section{INTRODUCTION}

Chronic illness has become an extensively debated topic in current practice, where the prevalence of $\mathrm{CCF}$ has been on the rise and is one of the main causative factors of mortality in recent years. ${ }^{1-3}$. With an increase in the proportion of ageing population in Singapore, more Singaporeans are suffering from multiple comorbidities and serious adverse events (SAEs), including high cholesterol levels and hypertension. ${ }^{4}$ Therefore, the patients should be encouraged to adopt lifestyle modifications after discharge from hospitals, like weight management and smoking cessation programmes to improve their health status. ${ }^{5}$ Despite these post-discharge treatments being put in place, the outlook for patients with CCF remains poor, exceeding $60 \%$ deaths at five years after first diagnosis. ${ }^{6}$ Ultimately, it is instrumental for patients with CCF to have an effective follow-up planning postdischarge from the hospital.

\section{CONGESTIVE CARDIAC FAILURE (CCF)}

CCF arises when the heart is incapable of pumping an adequate amount of blood to meet the bodies' need for oxygen. This can result in a build-up of fluid in the lungs and other vital organs. ${ }^{7}$ Because of the increased pressure in the lungs, the patient will present with a cough and dyspnea. Following this, swelling will be seen in the lower limbs as the heart is inefficient at managing venous return. ${ }^{5}$ At present, $\mathrm{CCF}$ is seen as the main cardiac cause for hospital admissions in Singapore, accounting for about $25 \%$ of all hospital stays. ${ }^{8}$ Moreover, CCF contributes to an alarming mortality rate of $29.6 \%$, which implies that roughly 1 out of 3 deaths in Singapore are caused by CCF. ${ }^{9}$ However, the mortality data may be under-reported, which in turn may not reflect the true incidence of deaths caused by CCF.

In addition to the high mortality rates of $\mathrm{CCF}$, it is also rapidly becoming one of the contributing factors of functional impairments among older adults in Singapore, thus having a significant impact on caregivers following discharge. ${ }^{10,11}$ Due to their physical limitations, individuals with CCF are often dependent on their caregivers to assist them with their activities of living (ALs) upon discharge, such as transferring and bathing. Also, patients with $\mathrm{CCF}$ often experience unrecognized postdischarge deterioration in their health status, which can lead to cardiac arrest making it hard for patients and their caregivers to recognize which in turn, may place a huge burden on them. ${ }^{13}$ Poor health outcomes have also become more prominent after discharge, with increased hospital readmission rates and higher risks of dying after being hospitalized with $\mathrm{CCF}$, as compared to before admission to the hospital. ${ }^{14-16}$ Findings from studies done in 2009 and 2010, have further concluded that the poor clinical outcomes were mainly caused by two major contributing factors: comorbidity and poor post-discharge follow-up planning. ${ }^{17-18}$ 


\section{POST-DISCHARGE RAPID RESPONSE TEAMS (RRTS)}

Rapid Response Teams (RRTs) represent a group of healthcare personnel who detects early clinical signs of post-discharge decline in patients. Their role is to expedite critical care expertise and prevent the adverse effects of CCF such as cardiac arrest, thereby potentially minimizing the mortality rates of patients with CCF. ${ }^{19,20}$ International evidence suggests that the use of RRTs in an acute hospital can help to promote a 50\% decrease in the incidence of cardiac arrests outside the intensive care unit and a $17 \%$ drop in the occurrence of cardiopulmonary arrests. ${ }^{21}$ RRTs have also helped to lower the number of unnecessary transfers to high-dependency care units by $30 \% .^{22-23}$ In light of the positive impacts of RRT reported in other countries, it is proposed that the post-discharge RRTs could also be utilized in Singapore healthcare institutions, specifically hospitals' cardiac departments. The aims of implementing post-discharge RRTs in the acute hospitals would be to improve early intervention and the clinical status of CCF patients, and decrease the incidence of cardiac arrests and deaths after discharge from the hospitals.

The post-discharge RRT would comprise of an inpatient multi-disciplinary team, led by a critical care advanced practice nurse (APN). The team will include two doctors specialized in cardiac emergency, a nurse clinician and a respiratory therapist. The APN in-charge would be given the autonomy to work independently of the primary doctor. The APN would also be empowered to request urgent investigations, prescribe medications and discuss Advance Care Planning (ACP) with the patients and their caregivers. This would allow for early assessment of the patient's health condition to detect signs of post-discharge clinical instability. ${ }^{24-25}$ Moreover, the team must be ready to respond immediately and should be in the hospital and accessible, to deliver top-notch critical care when required. ${ }^{26}$ For these reasons, the post-discharge RRT will be situated in the inpatient setting for the best response time (within five minutes), like that of an on-call cardiac medical team.

RRTs can be triggered by healthcare professionals, based on their perceptions of abnormal vital signs and the clinical judgment of potential deterioration in post-discharge $\mathrm{CCF}$ patients, such as a sudden drop in heart rate or blood pressure. ${ }^{27}$ ${ }^{29}$ Healthcare personnel should only activate RRTs if they have established that there is a decline in the patient's clinical status. ${ }^{30}$ This is further supported by a study conducted in 1999, which reported that clinical deterioration, including hemodynamic instability and acute respiratory insufficiency, were the usual triggers for activation of a RRT. ${ }^{21}$ These early warning scores will be utilized to initiate the post-discharge RRTs.

In contrast, research has demonstrated that the most recent innovation to post-discharge RRT is that it could be directly activated by the caregivers, without informing the primary care team first. ${ }^{31}$ In these cases, it is important that the patients and their caregivers understand that the post-discharge RRT might take some time to respond to the activation due to the complex illness trajectory of CCF. ${ }^{20,32}$

\section{SEARCH PROCESS}

The following databases were utilized to search for relevant manuscripts: CINAHL and Ovid Medline. The search was restricted only to peer-reviewed publications within the last 10 years. 14 articles met these criteria; three papers (two reviews and one quantitative) were chosen out of these 14 manuscripts to help critically analyze the proposed post-discharge RRTs in a Singapore's acute clinical setting. There are two distinct themes of the barriers towards implementation of post-discharge RRT that emerged from the literature review: (1) lack of self-efficacy in recognizing deterioration and activating RRT in the acute medical ward and (2) perception of inter-professional and intraprofessional hierarchies in the ward which caused the delay in rendering care for deteriorating $\mathrm{CCF}$ patients during the postdischarge period.

\section{A. Barriers to Implementing Post-discharge RRT}

\section{Table 1: Barriers to Implementing Post-discharge RRT}

\section{Lack of self-efficacy}

Nurses who have less than two years of experience working in the wards are likely to have doubts about their abilities to detect decline in a patient's health status. Thus, these nurses tend to use subjective strategies, like their intuition and pattern recognition, in order to identify clinical signs of decline rather than using a more objective assessment, i.e. vital signs. Such subjective methods, used by inexperienced nurses, may not be effective in detecting the sudden deterioration in patients' conditions which in turn, have a detrimental impact on the CCF patients. ${ }^{33}$ This knowledgepractice gap is also noticeable in novice nurses, who are unable to execute their knowledge in an emergency. ${ }^{34}$ Furthermore, novice nurses tend to miss the downward trends of clinical decline due to the lack of routine assessment. ${ }^{35}$ These novice nurses are also reluctant to ask the senior nurses for help if they are unsure of the deterioration in patients' clinical status. ${ }^{31,36}$ This implies that the healthcare professionals have fallen short of the organisation's expectations in rendering excellent care to the patients.

\section{Hierarchical barriers}

The inter-professional and intra-professional hierarchies are usually accepted by the healthcare professionals. However, these hierarchical barriers are problematic to overcome, and are often a hindrance in providing quality care for deteriorating patients. ${ }^{37}$ These working relationships may become difficult when the rest of the care team inhibit the nurse in-charge from obtaining help from the RRT. ${ }^{38}$ This is particularly problematic as having effective relationships is one of the salient features of a successful group. There are also barriers within the interdisciplinary hierarchy due to a varying extent of trust and collaboration. The differing viewpoints of the duties of the RRT may lead to levels of mistrust between the care team and the RRT, which in turn may influence the decisions to activate the RRT in emergency situations. $^{39}$ 


\section{B. Solutions to Minimise Barriers}

- A training session will be carried out before the initiation of post-discharge RRTs. The aim of this will be to educate healthcare professionals about signs of clinical deterioration. It will particularly focus on the novice nurses to neutralize the resistance towards escalating to the RRT. ${ }^{40}$

- The interdisciplinary simulation of RRT escalation is incorporated in the RRT training to help the nurses to gain confidence in communicating with the rest of the primary care team and the RRT, in the event that a patient declines. As a result of this training, nurses can gain knowledge on RRTs as well as gain experience required to recognize early signs of clinical deterioration in patients with CCF post-discharge. This in turn, may result in rendering excellent care to the patients that helps to improve their quality of life. A cornerstone of RRT activation is that, the nurses have the knowledge to detect the early warning signs evident in declining patients. ${ }^{41}$

SWOT ANALYSIS ${ }^{42,43}$

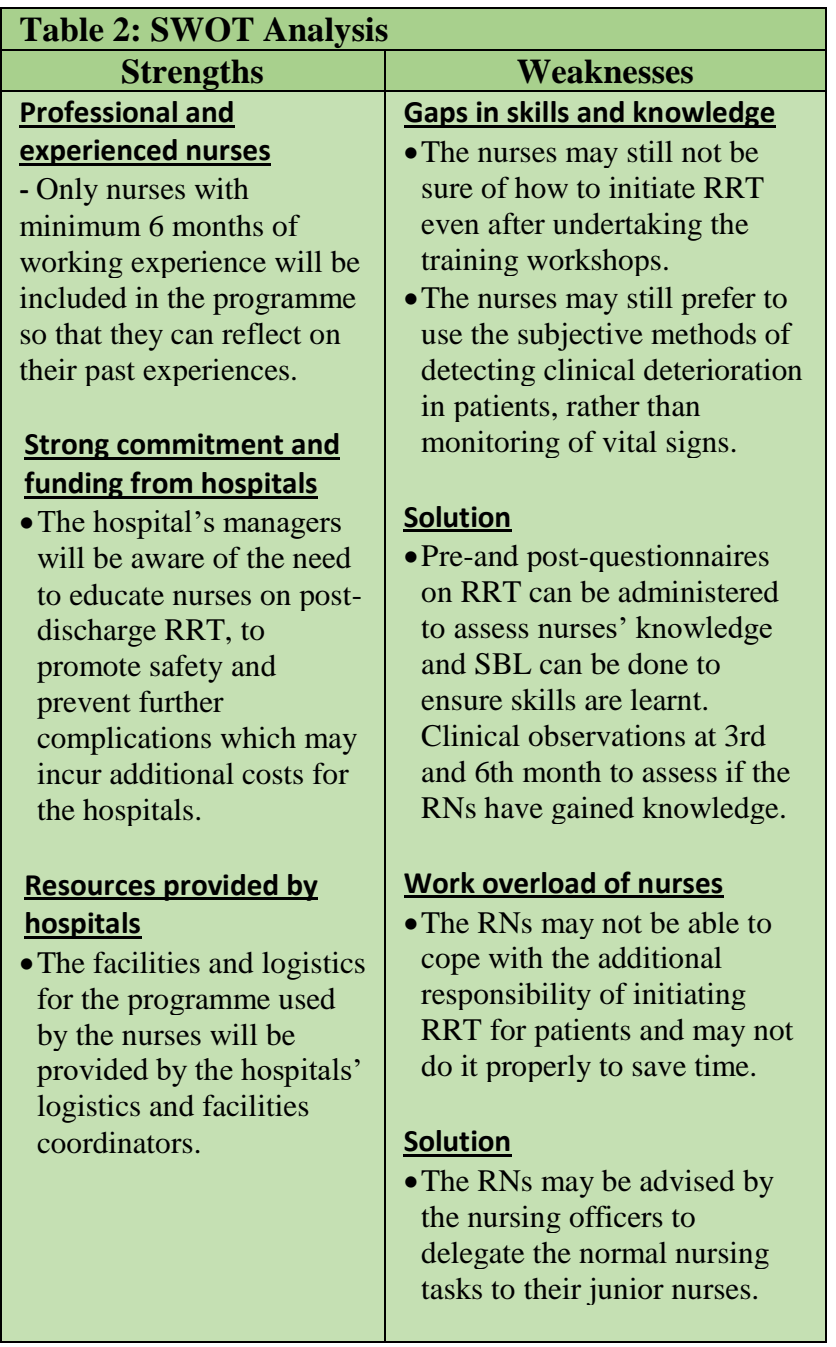

\begin{tabular}{|c|c|}
\hline Opportunities & Threats \\
\hline $\begin{array}{l}\text { Rising prevalence of } \\
\text { patients who are } \\
\text { experiencing SAEs and } \\
\text { sudden deterioration in } \\
\text { Singapore. } \\
\text { - This could further stress } \\
\text { the significance of } \\
\text { increasing knowledge on } \\
\text { use of early warning signs } \\
\text { to detect sudden changes } \\
\text { in patients' conditions } \\
\text { and trigger post-discharge } \\
\text { RRT. }\end{array}$ & $\begin{array}{l}\text { The importance of knowledge } \\
\text { and skills of implementing RRT } \\
\text { post-discharge on } \\
\text { deteriorating ward patients } \\
\text { may not be addressed. } \\
\text {-Paucity of published evidence } \\
\text { which discuss post-discharge } \\
\text { RRT, specifically for } \\
\text { deteriorating ward patients. } \\
\text { Solution } \\
\text { - Variety of teaching methods } \\
\text { will be used in the } \\
\text { programme, such as PBL with } \\
\text { group-work sessions and SBL } \\
\text { to enhance knowledge and } \\
\text { hone skills on recognising } \\
\text { early warning signs and } \\
\text { triggering post-discharge } \\
\text { RRT. }\end{array}$ \\
\hline
\end{tabular}

\section{CONCLUSION}

This paper has reviewed the need for the management of people with CCF to be more flexible and responsive to patient's needs. Moreover, it has outlined a proposal for implementing RRTs in hospital cardiac departments with a view to improving early intervention and the clinical status of CCF patients. The evidence reviewed highlights how RRTs can and do decrease the incidence of cardiac arrest and lower mortality after discharge from the hospital. Moreover, it has been argued that such teams would improve care, treatment and prevent deterioration. The paper has also highlighted some of the challenges to the implementation of RRTs in Singapore. The lack of self-efficacy and hierarchical barriers are identified as the two most prominent challenges to implementing postdischarge RRT. The SWOT Analysis has been utilized to review the efficacy of initiation of post-discharge RRT.

\section{REFERENCES}

[1] Hunt, S.A., Abraham, W.T., Chin, M.H., Feldman, A.M., Francis, G.S., Ganiats, T.G., Jessup, M., Konstam, M.A., Mancini, D.M., Michl, K., Oates, J.A., Rahko, P.S., Silver, M.A., Stevenson, L.W. and Yancy, C.W. (2009) 'Focused update incorporated into the ACC/AHA 2005 Guidelines for the diagnosis and management of heart failure in adults: A report of the American College of Cardiology Foundation/American Heart Association Task Force on practice guidelines developed in collaboration with the international society for heart and lung transplantation', Journal of American College of Cardiology, 53(15), pp. 1-90.

[2] Lloyd-Jones, D., Adams, R.J., Brown, T.M., Carnethon, M., Dai, S., De Simone, G., Ferguson, T.B., Ford, E., Furie, K., Gillespie, C., Go, A., Greenlund, K., Haase, N., Hailpern, S., Ho, P.M., Howard, V., Kissela, B., Kittner, S., Lackland, D., Lisabeth, L., Marelli, A., McDermott, M.M. Meigs, J., Mozaffarian, D., Mussolino, M., Nichol, G., Roger, V.L., Rosamond, W., Sacco, R., Sorlie, P., Stafford, R., Thom, T., WasserthielSmoller, S., Wong, N.D. and Wylie-Rosett, J. (2010) 'Executive Summary: heart disease and stroke statistics - 2010 update: a report from the American Heart Association', Circulation: Heart Failure, 121(7), pp. 948-954. 
[3] Roger, V.L., Go, A.S., Lloyd-Jones, D.M., Benjamin, E.J., Berry, J.D., Borden, W.B., Bravata, D.M., Dai, S., Ford, E.S., Fox, C.S., Fullerton, C.J., Gillespie, C., Hailpern, S.M., Heit, J.A., Howard, V.J., Kissela, B.M. and Kittner, S.J. (2012) 'Heart disease and stroke statistics-2012 update: a report from the American Heart Association', Circulation, 125, pp. 2 220.

[4] Metra, M., Cotter, G., El-Khorazaty, J., Davison, B.A., Milo, O. Carubelli, V., Bourge, R.C., Cleland, J.G., Jondeau, G., Krum, H., O'Connor, C.M., Parker, J.D., Torre-Amione, G., van Veldhuisen, D.J., Rainisio, M., Kobrin, I., McMurray, J.J. and Teerlink, J.R. (2015) 'Acute heart failure in the elderly: Differences in clinical characteristics, outcomes, and prognostic factors in the VERITAS Study', Journal of Cardiac Failure, 21, pp. 179-188.

[5] Kemp, C.D. and Conte, J.V. (2012) 'The pathophysiology of heart failure', Cardiovascular Pathology, 21, pp. 365-371.

[6] Blair, J.E., Khan, S., Konstam, M.A., Swedberg, K., Zannad, F., Burnett, J.C. Jr., Grinfeld, L., Maggioni, A.P., Udelson, J.E., Zimmer, C.A., Ouyang, J., Chen, C.F. and Gheorghiade, M. (2009) 'EVEREST Investigators. Weight changes after hospitalization for worsening heart failure and subsequent re-hospitalization and mortality in the EVEREST trial', European Heart Journal, 30, pp. 1666-1673.

[7] American Heart Association. (2016) Congestive heart failure and congenital defects. Dallas: American Heart Association.

[8] Ng, T.P. and Niti, M. (2003) 'Trends and ethnic differences in hospital admissions and mortality for congestive heart failure in the elderly in Singapore, 1991 to $1998^{\prime}$, Heart, 89, pp. 865-870.

[9] Singapore Heart Foundation (SHF). (2012) Principal causes of death. Singapore: Singapore Heart Foundation.

[10] Gheorghiade, M. and Bonow, R.O. (2010) 'Heart failure: early follow-up after hospitalization for heart failure', Nature Reviews Cardiology, 7, pp. $422-424$.

[11] Molloy, G.J., Johnson, D.W. and Witham, M.D. (2005) 'Family caregiving and congestive heart failure. Review and analysis', European Journal of Heart Failure, 7, pp. 592-603.

[12] Metra, M., Gheorghiade, M., Bonow, R.O. and Cas, L.D. (2010) 'Postdischarge Assessment After a Heart Failure Hospitalization', Circulation: Heart Failure, 122, pp. 1782-1785.

[13] Bertaut, Y., Campbell, A. and Goodlett, D. (2008) 'Implementing a rapidresponse team using a nurse-to-nurse consult approach', Journal of Vascular Nursing 26, pp. 37-42.

[14] Gheorghiade, M. and Pang, P.S. (2009) 'Acute heart failure syndromes', Journal of the American College of Cardiology, 53, pp. 557-573.

[15] Pang, P.S., Komajda, M. and Gheorghiade, M. (2010) 'The current and future management of acute heart failure syndromes', European Heart Journal, 31, pp. 784-793.

[16] Ross, J.S., Chen, J., Lin, Z., Bueno, H., Curtis, J.P., Keenan, P.S., Normand, S.L., Schreiner, G., Spertus, J.A., Vidán, M.T., Wang, Y., Wang, Y. and Krumholz, H.M. (2010) 'Recent national trends in readmission rates after heart failure hospitalization', Circulation: Heart Failure, 3, pp. 97-103.

[17] Jessup Jessup, M., Abraham, W.T., Casey, D.E., Feldman, A.M., Francis, G.S., Ganiats, T.G., Konstam, M.A., Mancini, D.M., Rahko, P.S., Silver, M.A., Stevenson, L.W. and Yancy, C.W. (2009) 'Focused update: ACCF/AHA guidelines for the diagnosis and management of heart failure in adults: a report of the American College of Cardiology Foundation/American Heart Association Task Force on Practice Guidelines: developed in collaboration with the International Society for Heart and Lung Transplantation', Circulation: Heart Failure, 119, pp. 1977-2016.

[18] Lindenfeld, J., Albert, N.M., Boehmer, J.P., Collins, S.P., Ezekowitz, J.A., Givertz, M.M., Katz, S.D., Klapholz, M., Moser, D.K., Rogers, J.G., Starling, R.C., Stevenson, W.G., Tang, W.H., Teerlink, J.R. and Walsh, M.N. (2010) 'HFSA 2010 comprehensive heart failure practice guideline', Journal of Cardiac Failure, 16, pp. 475-539.

[19] Institute for Clinical Systems Improvement (ICSI). (2011) Health care protocol: Rapid response team, $4^{\text {th }}$ ed. Minnesota: Institute for Clinical Systems Improvement.

[20] Jones, D.A., DeVita, M.A. and Bellomo, R. (2011) 'Rapid-response teams', New England Journal of Medicine, 365(2), pp. 139-146.
[21] Buist, M.D., Jarmolowski, E., Burton, P.R., Bernard, S.A., Waxman, B.P and Anderson, J. (1999) 'Recognising clinical instability in hospital patients before cardiac arrest or unplanned admission to intensive care. A pilot study in a tertiary-care hospital', Medical Journal of Australia, 171(1), pp. 22-25.

[22] Bellomo, R., Goldsmith, D., Uchino, S., Buckmaster, J., Hart, G., Opdam, H., Silvester, W., Doolan, L. and Gutteridge, G. (2004) 'Prospective controlled trial of effect of medical emergency team on postoperative morbidity and mortality rates', Critical Care Medicine, 32(4), pp. 916921.

[23] Goldhill, D.R., Worthington, L., Mulcahy, A., Tarling, M. and Summer, A. (1999) 'The patient-at-risk team: identifying and managing seriously ill ward patients', Anaesthesia, 54(9), pp. 853-860

[24] Taguti, P.D., Dotti, A.Z., Araujo, K.P., Pariz, P.S., Dias, G.F., Kauss, I.A., Grion, C.M. and Cardoso, L.T. (2013) 'The performance of a rapid response team in the management of code yellow events at a university hospital', Revista Brasileira de Terapia Intensiva, 25(2), pp. 99-105.

[25] Jolley, J., Bendyk, H., Holaday, B., Lombardozzi, K.A. and Harmon, C. (2007) 'Rapid response teams: do they make a difference?', Dimensions of Critical Care Nursing, 26(6), pp, 253-260.

[26] Cretikos, M.A., Chen, J., Hillman, K.M., Bellomo, R., Finfer, S.R. and Flabouris, A. (2007) 'The effectiveness of implementation of the medical emergency team (MET) system and factors associated with use during the MERIT study', Critical Care Resuscitation, 9, pp. 206-212.

[27] Lee, A., Bishop, G., Hillman, K.M. and Daffurn, K. (1995) 'The medical emergency team', Anaesthesia and Intensive Care, 23, pp. 183-186.

[28] Thomas, K., Van Oyen Force, M., Rasmussen, D., Dodd, D. and Whildin, S. (2007) 'Rapid response team: challenges, solutions, benefits', Critical Care Nurse, 27, pp. 20-27.

[29] Ray, E.M., Smith, R., Massie, S., Erickson, J., Hanson, C., Harris, B. and Willis, T.S. (2009) 'Family alert: Implementing direct family activation of a paediatric rapid response team', Joint Commission Journal on Quality \& Patient Safety, 35(11), pp. 575-580.

[30] Solomon, S.D., Dobson, J., Pocock, S., Skali, H., McMurray, J.J., Granger, C.B., Yusuf, S., Swedberg, K., Young, J.B., Michelson, E.L. and Pfeffer, M.A. (2007) 'Candesartan in Heart Failure: Assessment of Reduction in Mortality and Morbidity (CHARM) Investigators. Influence of nonfatal hospitalization for heart failure on subsequent mortality in patients with chronic heart failure', Circulation: Heart Failure, 116, pp. 1482-1487

[31] Cooper, S., McConnell-Henry, T., Cant, R., Porter, J., Missen, K., Kinsman, L., Endacott, R. and Scholes, J. (2011) 'Managing deteriorating patients: registered nurses' performance in a simulated setting', The Open Nursing Journal, 5(1), pp. 120-126.

[32] Cooper, S., Cant, R., Porter, J., Missen, K., Sparkes, L., McConnellHenry, T. \& Endacott, R. (2013) Managing patient deterioration: assessing teamwork and individual performance. Emergency Medicine Journal, 30(5), pp. 377-381

[33] Endacott, R., Kidd, T., Chaboyer, W. and Edington, J. (2007) 'Recognition and communication of patient deterioration in regional hospital: a multi-methods study', Australian Critical Care, 20(3), pp. 100-105.

[34] Hillman, K., Chen, J. and Cretikos, M. (2005) 'Introduction of the medical emergency team (MET) system: a cluster-randomised controlled trial. MERIT study investigators', Lancet, 365(9477), pp. 2091-2097.

[35] Sundararajan, K., Flabouris, A. and Thompson, C. (2016) 'Diurnal variation in the performance of rapid response systems: the role of critical care services - a review article', Journal of Intensive Care, 4(15), pp. 111.

[36] Roberts, K., Bonafide, C., Paine, C., Paciotii, B., Tibbetts, K., Keren, R. Barg, F.K. and Holmes, J.H. (2014) 'Barriers to Calling for Urgent Assistance Despite a Comprehensive Pediatric Rapid Response System', American Journal of Critical Care, 23(3), pp. 223-229.

[37] Hall, P. (2005) 'Professional cultures as barriers', Journal of Interprofessional Care, 19, pp. 188-196.

[38] Liaw, S.Y., Scherpbier, A., Klainin-Yobas, P. and Rethans, J.J. (2011) 'A review of educational strategies to improve nurses' roles in recognizing and responding to deteriorating patients', International Nursing Review, 58(3), pp. 296-303 
[39] Leonard, B., Shuhaibar, E.L. and Chen, R. (2010) 'Nursing student perceptions of interprofessional team education using high-fidelity simulation', Journal of Nursing Education, 49, pp. 628-631.

[40] David, F. (1993) Strategic Management, $4^{\text {th }}$ ed. New York: Macmillan Publishing Company.

[41] Glaister, K.W. and Falshaw, J.R. (1999) 'Strategic planning still going strong', Long Range Planning, 32(1), pp. 107-116.
[42] Powell, C.R. (1999) SWOT Analysis. Available at: http://www.indiana.edu/ jobtalk/HRMWebsite/hrm/articles/hrm/SWOT analysis.pdf (Accessed on: 22 ${ }^{\text {nd }}$ February 2017).

[43] Hill, T. and Westbrook, R. (1997) 'SWOT Analysis: It's Time for a Product Recall’, Long Term Planning, 30(1), pp. 46-52. 